(A) Check for updates

Cite this: Food Funct., 2021, 12, 761

\title{
Enriching street-vended zobo (Hibiscus sabdariffa) drink with turmeric (Curcuma longa) to increase its health-supporting properties
}

\author{
Folake Idowu-Adebayo, (D) a,b Mary J. Toohey, ${ }^{a}$ Vincenzo Fogliano (D) a and \\ Anita R. Linnemann*a
}

\begin{abstract}
Street-vended foods are cheap, readily available and have been currently identified as possible means for micronutrient fortification in an effort to prevent malnutrition in developing countries. The effect of enriching street-vended zobo drink (Hibiscus sabdariffa) with turmeric (Curcuma longa) was studied to assess the potential to increase health-supporting properties for its consumers. Two processing methods were tested: boiled turmeric root in zobo and addition of fresh turmeric paste to zobo in different concentrations. Vitamin C in turmeric-fortified zobo ranged from 496-725 $\mu \mathrm{g}$ per $100 \mathrm{~mL}$, delphinidin-3sambubioside from 52-69 mg per $100 \mathrm{~mL}$, and cyanidin-3-sambubioside from 21-27 mg per $100 \mathrm{~mL}$. Micronutrients ranged from $10.9-14 \mathrm{mg} \mathrm{L}^{-1}$ and $2.19-2.67 \mathrm{mg} \mathrm{L}^{-1}$ for iron and zinc, respectively. Folic acid, vitamin $C$, anthocyanins and iron showed the highest amounts in the $2 \%$ boiled turmeric zobo samples. Ferulic acid (0.16-2.03 mg per $100 \mathrm{~mL}$ ), and chlorogenic acid (20-24 mg per $100 \mathrm{~mL}$ ) did not show the same statistically significant improvement for $2 \%$ boiled turmeric-fortified zobo. The zobo samples with turmeric paste consistently had lower values of vitamins, polyphenols and minerals in comparison with the boiled turmeric-fortified zobo samples. Turmeric-fortified zobo can play a role in a healthy diet by its health-supporting properties. Consumption of a typical one serving of $500 \mathrm{~mL}$ (representative packaged bottle size of zobo drink by the street vendors in Nigeria) of turmeric-fortified zobo would contribute $63-88 \%$ DV and $18-23 \%$ DV of iron and zinc. Overall, fortification with boiled turmeric improves the antioxidant and nutritional quality of zobo, specifically regarding vitamin $\mathrm{C}$, delphinidin-3sambubioside and iron.
\end{abstract}

Received 3rd November 2020, Accepted 20th December 2020 DOI: $10.1039 / \mathrm{dOfo} 02888 \mathrm{f}$ rsc.li/food-function
Sudan and Egypt (where it is also called "drink of the Pharaohs"). It is commonly known as karkanji, wonjo, zobo and bissap in Chad, Gambia, Nigeria and Senegal, respectively. In Asia, it is named mei gui qie, karkade and krajeap in China, Saudi Arabia and Thailand, respectively. It is recognized as asam belanda, asam susur, asam paya or ribena, in Malaysia. The Indian subcontinent calls it by many tribal names such as Indian sorrel, mesta, lal ambari, patwa, amta and amti. It is known as rosella in Australia and flor de Jamaica in Mexico. In Europe, it is referred to as Congo, Jamaica and karkade in France, Spain and Switzerland, respectively. ${ }^{3-6}$ The many names for this crop reflect its ubiquity and popularity.

Scientific studies have revealed that zobo calyces are rich in flavonoids, minerals, organic acids, vitamins and polyphenol compounds, which all contribute to the nutritive value and biological activity of the drink. ${ }^{7-9}$ The two major anthocyanin compounds in H. sabdariffa calyces are delphinidin-3-sambubioside and cyanidin-3-sambubioside. These anthocyanins have been reported as unstable and likely to degrade during the preparation of the drink. However, processing conditions

\footnotetext{
${ }^{a}$ Food Quality and Design Group, Department of Agrotechnology and Food Sciences, Wageningen University and Research Centre, Wageningen, The Netherlands

${ }^{b}$ Dept of Food Science and Technology, Federal University Oye-Ekiti, Nigeria. E-mail: anita.linnemann@wur.nl
} 
such as extraction temperature, protection from UV light, and addition of food-grade organic acid have been reported to impact anthocyanin stability. ${ }^{10}$ Recent study characterized the physiochemical properties and non-volatiles of $H$. sabdariffa calyces cultivated in Australia, China, Chad, Malaysia, Mexico, Nigeria, Sudan and Thailand. ${ }^{3}$ They concluded that variation found in the characterization of the $H$. sabdariffa calyces grown in different countries were mainly due to the practice of sun drying. Sun drying is a traditional processing method to obtain dried $H$. sabdariffa calyces that are easy to transport and store in developing countries, including Nigeria.

Due to zobo's popularity, any nutritional improvement of the drink is likely to benefit many people in Nigeria, where malnutrition is a major concern. ${ }^{11}$ One approach to further augment zobo would be through food-to-food fortification, which is a solution for the population without changing food consumption patterns in a radical way. ${ }^{12}$ Fortification of the zobo drink with another food ingredient that is rich in bioactive compounds could also improve the stability of the anthocyanin content, based on reports that the structure of the organic acid and food matrix in which it is combined would have a strong effect on the stability of the anthocyanins. ${ }^{10}$

Turmeric (Curcuma longa) can be used in zobo to fortify and potentially improve the antioxidant and nutritional quality of the drink. It is a shallow-rooted crop that is commonly grown throughout Nigeria, making it production and sales regionally and economically beneficial. ${ }^{13}$ Turmeric contains curcumin, a well-known polyphenol with many acclaimed health benefits in addition to anti-inflammatory and antioxidant properties that have been researched extensively. ${ }^{14}$ In addition to curcumin, turmeric has been found to contain other antioxidants, such as ferulic acid. ${ }^{15}$ Ferulic acid exhibits anti-inflammatory, antidiabetic, and anticancer activity. In addition, ferulic acid has protective effects on organs, tissues, and cells of the cardiovascular system and skin. ${ }^{16}$

In this study, turmeric was added to zobo in different concentrations using two processing methods: boiling of turmeric root in the zobo and addition of fresh turmeric paste to the final zobo drink. The research aimed at determining if addition of turmeric could improve the antioxidant and nutritional profile of zobo drink. Overall, the effect of processing on the antioxidant and nutritional quality of turmeric-fortified zobo was established.

\section{Materials and methods}

\subsection{Materials}

2.1.1. Food ingredients. Dried zobo ( $H$. sabdariffa) calyces were purchased from Dutse market, Abuja, Nigeria. Turmeric roots were purchased from Omuooke-Ekiti market, Ekiti State, Nigeria.

2.1.2. Chemicals. Ascorbic acid, folic acid, chlorogenic acid, and trans-ferulic acid were purchased from Sigma Aldrich (St Louis, MO, USA). Delphidin-3-sambubioside chloride and cyanidin-3-sambubioside chloride were purchased from
Extrasynthese (France). All solvents in the experiments were HPLC grade.

\subsection{Sample preparation}

2.2.1. Preparation of turmeric paste. Turmeric paste was made by combining $40 \mathrm{~g}$ of finely chopped turmeric root (Fig. 1a) with $80 \mathrm{~mL}$ of tap water. The two components were blended, using a Waring Commercial blender (United States), for approximately four min at the highest speed, until smooth. The final product can be seen in Fig. $1 \mathrm{~b}$.

2.2.2. Preparation of controls. Five control samples were produced: the turmeric controls consisted of turmeric in water, using two different preparation methods and two different concentrations. The first method consisted of boiling water with chopped turmeric root pieces (Fig. 1a) of approximately $2 \times 2 \mathrm{~mm}$ for five $\mathrm{min}$. The turmeric pieces were allowed to soak in the water overnight, followed by sieving in the morning. The second method consisted of boiling water and allowing the water to cool overnight. The following morning, fresh turmeric paste was added and stirred. Both methods included utilizing turmeric at two different concentrations, $2 \%$ and $6 \%$ based on the weight of the water during the addition: water with boiled turmeric $2 \% \mathrm{w} / \mathrm{w}$, water with boiled turmeric $6 \% \mathrm{w} / \mathrm{w}$, water with fresh turmeric paste $2 \%$ $\mathrm{w} / \mathrm{w}$, and water with fresh turmeric paste $6 \% \mathrm{w} / \mathrm{w}$. The zobo control was prepared by boiling water and $H$. sabdariffa calyces, in a ratio of $2: 25$ by weight, in a large pot for five min. The pot was then removed from the heat source and allowed to soak overnight.

Next, the beverage was sieved. The final beverage samples are shown in Fig. 1c.

2.2.3. Preparation of turmeric-fortified zobo samples. Four turmeric-fortified zobo samples were produced: zobo with boiled turmeric $2 \% \mathrm{w} / \mathrm{w}$, zobo with boiled turmeric $6 \% \mathrm{w} / \mathrm{w}$, zobo with fresh turmeric paste $2 \% \mathrm{w} / \mathrm{w}$, and zobo with fresh turmeric paste $6 \% \mathrm{w} / \mathrm{w}$. The turmeric-fortified zobo samples

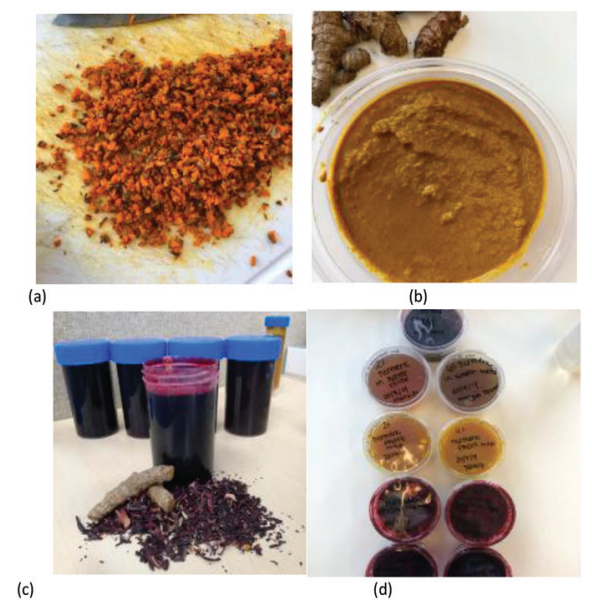

Fig. 1 (a) Chopped turmeric for boiled turmeric samples. (b) Freshly blended turmeric for turmeric paste samples. (c) and (d) Final samples ready for analysis. 
were all prepared with water and $H$. sabdariffa calyces, in a ratio of $2: 25$ by weight. The zobo with boiled turmeric was prepared by boiling $H$. sabdariffa calyces with finely chopped turmeric root pieces for five min, followed by soaking at room temperature overnight and sieving in the morning. The turmeric pieces were added at either $2 \%$ or $6 \%$ of the weight of the water during the addition. The zobo with fresh turmeric paste was made using the same method as the zobo control, but with the addition of either $2 \%$ or $6 \%$ turmeric paste after the overnight soak and sieving. A schematic representation is presented in Fig. 2.

2.2.4. Freeze drying. Samples were freeze dried for 140-144 h in a freeze-dryer (Martin Christ Gefriertrocknungsanlagen $\mathrm{GmbH}$ ), until all moisture was evaporated. The sample was weighed before and after freeze drying to accurately calculate original values.

\subsection{Chemical analysis}

\subsubsection{Measurement of $\mathbf{p H}$}

2.3.1.1. $p H$. The $\mathrm{pH}$ of the zobo samples was measured with a pH meter ( $\mathrm{pHenomenal} \mathrm{VWr} \mathrm{pH} 1000 \mathrm{~L}$ ).

\subsubsection{Proximate analysis}

2.3.2.1. Moisture content. The moisture content was determined following the method described by Ekanem. ${ }^{17}$

2.3.2.2. Ash content. The ash content was measured by heating the sample in a Carbolite CSF1100 ashing oven at $550{ }^{\circ} \mathrm{C}$ for $6 \mathrm{~h}$, after the method of Ekanem. ${ }^{17}$

The ash content was calculated with the formula below.

$$
\begin{aligned}
\text { Ash content }= & \frac{\text { Weight of the sample after ashing }}{\text { Weight of the sample transferred before ashing }} \\
& \times 100 \%
\end{aligned}
$$

2.3.2.3. Crude protein content. The protein content was analysed using LECO CN 628 Dumas analyser, Germany. Freezedried samples and blank samples with cellulose (Sigma Aldrich 310697, US) were weighed in tin cups (Interscience, Belgium) and put in a sample tray. The samples were then oxi-

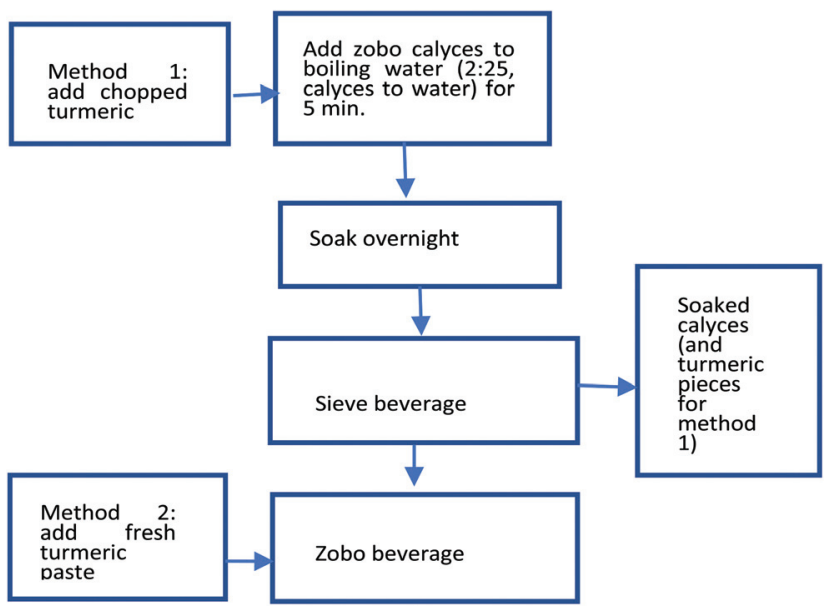

Fig. 2 Zobo production flow scheme for the two methods of the study. dised in the Dumas metal column filled with chemicals at high temperature and water filters in a separation column, on which nitrogen was separated and calculated into protein content. The standard nitrogen to protein conversion factor, 6.25 , was used to calculate the protein concentration. ${ }^{18}$

As all food fractions should add up to $100 \%$, the carbohydrate content was calculated by the formula: ${ }^{17}$

$$
\begin{aligned}
\text { Carbohydrate content }= & 100 \%-\text { moisture content } \\
& - \text { ash content }- \text { fat content } \\
& - \text { crude protein content. }
\end{aligned}
$$

2.3.3. Mineral determination. Mineral (iron and zinc) analysis was performed at the Chemisch Biologisch Laboratorium Bodem (CBLB), Wageningen, the Netherlands, according to the procedure described in the plant analysis procedure. ${ }^{19}$ Samples were destructed with $\mathrm{HNO}_{3}-\mathrm{HCl}$ (aqua regia) and measured with the ICP-AES method for iron and zinc.

\subsubsection{Vitamin determinations}

2.3.4.1. Folic acid. Folic acid concentration was determined by HPLC as described by Chen et $a .^{20} \mathrm{~A}$ Thermo Scientific (Germany) Ultimate 3000 HPLC machine with RS diode array detector was used. Modifications made were: folic acid standards were prepared in $\mathrm{KH}_{2} \mathrm{PO}_{4}$ buffer at $\mathrm{pH}$ 8-9. Alltech prevail C18 5u column $(4.6 \times 250 \mathrm{~mm})$ was used. The samples were prepared by sonication of freeze-dried samples for $5 \mathrm{~h}$ at $40{ }^{\circ} \mathrm{C}$. Centrifugation followed at $4000 \mathrm{rpm}$ for seven min. Samples were then filtered into amber HPLC vials. Quantification based on measurement of peak areas was taken with UV detection at $283 \mathrm{~nm}$ for $25 \mathrm{~min}$.

2.3.4.2. Vitamin $C$. Ascorbic acid was determined as described by Hernández et $a .^{21}$ using a Thermofisher HPLC (Thermo Scientific, Germany). The samples containing zobo were diluted twice, while samples containing just water and turmeric were not diluted. A Varia Polaris 5 C18-A column (4.6 $\times 150 \mathrm{~mm}$ ) was used.

\subsubsection{Anthocyanin determinations}

2.3.5.1. Delphidin-3-sambubioside and cyanidin-3-sambubioside. Delphidin-3-sambubioside and cyanidin-3-sambubioside were determined using HPLC (Thermo Scientific, Germany). Zobo samples were prepared according to the previously mentioned protocol in 2.2.3. The zobo and water samples were extracted using $0.1 \% \mathrm{HCl}$ in methanol. $5 \mathrm{~mL}$ of sample was combined with $5 \mathrm{~mL}$ of extraction liquid in a $15 \mathrm{~mL}$ greiner tube and shaken for one $\mathrm{h}$ at maximum speed. All samples were then centrifuged at $3000 \mathrm{rpm}$ for $30 \mathrm{~min}$. Next, samples were filtered using $0.45 \mu \mathrm{m}$ RC filters into amber HPLC vials. HPLC analysis utilized 1\% formic acid in Milli-Q ${ }^{\circledR}$ water as eluent $\mathrm{A}$ and $100 \%$ methanol as eluent $\mathrm{B}$. The gradient elution started with 5\% (B), which increased to 60\% (0-20 min) and then to $100 \%$ (20-25 min). The conditions were held at $100 \%$ for $5 \mathrm{~min}$ prior to returning to $5 \%$ (30-31 $\mathrm{min})$ with a final isocratic run of $5 \% \mathrm{~B}$ (31-35 min). The flow rate was $1 \mathrm{ml} \mathrm{min}^{-1}$ and the injection volume was $20 \mu \mathrm{l}$. A Varian Polaris 5 C18-A column $(5 \mu \mathrm{m}, 4.6 \times 150 \mathrm{~mm})$ was used. Calibration curves for both delphidin-3-sambubioside and cyanidin-3-sambubioside were made by making a stock solution of $1 \mathrm{mg} \mathrm{mL}^{-1}$ in metha- 
nol. The stock solutions were stored at $-20^{\circ} \mathrm{C}$. The calibration curve consisted of seven calibration standards: 17.19-34.38-68.75-137.5-275-550 ( $\left.\mu \mathrm{g} \mathrm{ml} \mathrm{ml}^{-1}\right)$ of delphidin-3sambubioside and cyanidin-3-sambubioside. The UV-Vis spectrum of $510 \mathrm{~nm}$ was used for analyzing data from chromatograms.

2.3.6. Chlorogenic and ferulic acid determinations. Six samples including all zobo containing samples and water with boiled turmeric at both $2 \%$ and $6 \%$ were analyzed. Chlorogenic acid and ferulic acid were determined using method described by Beltrán-Debón et al. ${ }^{22}$ An Ultimate 3000 HPLC machine (Thermo Scientific, Germany) with RS diode array detector was used. Modifications made were: a Varian Polaris 5 C18-A $4.6 \times 150 \mathrm{~mm}$ column was used at a flow rate of $1 \mathrm{ml} \mathrm{min}{ }^{-1}$. Stock solutions of $1 \mathrm{mg} \mathrm{ml}^{-1}$ were made for chlorogenic acid and ferulic acid and stored at $-20^{\circ} \mathrm{C}$. A calibration curve for each component was prepared with six work solutions: 4.69-9.38-18.75-37.5-75-150 ( $\left.\mu \mathrm{g} \mathrm{mL}^{-1}\right)$. Fresh, liquid zobo samples were used and diluted two times with Milli-Q® ${ }^{\circledR}$ water/trifluoroacetic acid pH 2.5 before filtering. UV-Vis spectrum were recorded in the wavelength of $220 \mathrm{~nm}$ for both chlorogenic acid and ferulic acid.

\subsection{Statistical analysis}

Data were analysed using Microsoft Office 2016, Chromeleon 7 and IBM SPSS Statistics. Analysis was performed in triplicate with three independent batches for all samples except otherwise stated in section 2.3. The differences between the samples were determined using paired $t$-tests between batches of the same sample and assumed equal variance $t$-tests (twosample) between different sample means. To determine if data was normally distributed, the test of Shapiro-Wilk was used with $p<0.05$, where $H_{0}=$ data is normally distributed and $H_{\mathrm{a}}=$ data is not normally distributed.

\section{Results and discussion}

\section{1. $\mathrm{pH}$}

3.1.1. $\mathbf{p H}$. The $\mathrm{pH}$ of the zobo was measured to determine the amount of acid, which influences vitamin stability and measurements. The $\mathrm{pH}$ of zobo slightly increased with increasing turmeric concentration, and ranged between 2.4-2.6. The addition of turmeric increased the $\mathrm{pH}$ and higher concentrations of turmeric paste increased the $\mathrm{pH}$ further (Table 1).

An higher $\mathrm{pH}$, namely 3.6, was found by Ekanem ${ }^{17}$ using a lower ratio of hibiscus calyces $(1.5: 25)$. Furthermore in his study the zobo was boiled for a longer time (40 $\mathrm{min})$ and not soaked overnight. This could influence the composition of the extracts, thus influencing the $\mathrm{pH}$. Adesokan et al. ${ }^{23}$ reported an even higher $\mathrm{pH}$ of 3.94. Their preparation method used a ratio of $15: 25$, much higher than the ratio used in this research. Additionally, the calyces were added to boiling water and only allowed to soak for $15 \mathrm{~min}$. Consequently, the higher $\mathrm{pH}$ in literature might be due to the shorter time the hibiscus calyces were kept in the water. Letting the zobo soak overnight
Table $1 \mathrm{pH}$ and proximate composition (weight \%) of zobo control and turmeric-fortified zobo

\begin{tabular}{llllll}
\hline Samples & $\mathrm{pH}$ & Moisture & Ash & Protein & Carbohydrates $^{a}$ \\
\hline $\begin{array}{l}\text { Control (zobo } \\
\text { with 0\% }\end{array}$ & $2.4 \pm$ & $96.2 \pm$ & $0.47 \pm$ & $0.18 \pm$ & 3.1 \\
turmeric) & $0.01^{\mathrm{B}}$ & $0.29^{\mathrm{A}}$ & $0.03^{\mathrm{A}}$ & $0.01^{\mathrm{B}}$ & \\
$\mathbf{2 \%}$ boiled & $2.4 \pm$ & $95.9 \pm$ & $0.54 \pm$ & $0.23 \pm$ & 3.4 \\
turmeric in & $0.03^{\mathrm{ABC}}$ & $0.45^{\mathrm{AB}}$ & $0.06^{\mathrm{A}}$ & $0.01^{\mathrm{A}}$ & \\
zobo & & & & & \\
$\mathbf{6 \%}$ boiled & $2.6 \pm$ & $95.8 \pm$ & $0.56 \pm$ & $0.22 \pm$ & 3.4 \\
turmeric in & $0.02^{\mathrm{AC}}$ & $0.18^{\mathrm{AB}}$ & $0.06^{\mathrm{A}}$ & $0.01^{\mathrm{A}}$ & \\
$\begin{array}{l}\text { zobo } \\
\mathbf{2 \%} \text { fresh }\end{array}$ & $2.4 \pm$ & $95.9 \pm$ & $0.45 \pm$ & $0.18 \pm$ & 3.5 \\
turmeric & $0.01^{\mathrm{C}}$ & $0.15^{\mathrm{AB}}$ & $0.04^{\mathrm{A}}$ & $0.03^{\mathrm{AB}}$ & \\
$\begin{array}{l}\text { paste in zobo } \\
\mathbf{6 \%} \text { fresh }\end{array}$ & $2.5 \pm$ & $95.8 \pm$ & $0.47 \pm$ & $0.20 \pm$ & 3.5 \\
turmeric & $0.02^{\mathrm{A}}$ & $0.24^{\mathrm{B}}$ & $0.05^{\mathrm{A}}$ & $0.04^{\mathrm{AB}}$ & \\
paste in zobo & & & & & \\
& & & & &
\end{tabular}

Significant differences $(p<0.05)$ in the same column are indicated with different superscripts. ${ }^{a}$ The carbohydrate content was calculated from the other fractions to have an indication of the carbohydrate content of our samples.

allows for a longer extraction time, in which more acid compounds might be dissolved, thus resulting in the lower $\mathrm{pH}$ found in our study. The slight increase in $\mathrm{pH}$ by adding turmeric to zobo is unlikely to significantly affect product properties.

\subsection{Proximate composition}

3.2.1. Moisture content. The moisture content of the zobo control found in our study (Table 1) was in accordance with values found by Adeniji et $a .^{24}$ who measured the moisture content of commercial (95.1\% moisture) and locally prepared (94.5\% moisture) zobo. However, other authors reported lower moisture contents, in the range of $82-88 \%{ }^{17,25}$ The higher dry matter content they found could be due to the addition of flavouring ingredients, such as ginger and fruits, or sugar.

3.2.2. Ash content. For the ash content, values between $0.6-1.8 \%$ were reported in the literature..$^{24-26}$ The ash content in this study is slightly lower than this range, which can be explained by the moisture content of the zobo. Turmeric in water control samples contained $0.03-0.06 \%$ ash with $6 \%$ fresh turmeric paste in water having the highest value. However, zobo with boiled turmeric $2 \%$ and $6 \%$ had higher ash contents than the zobo control and the $2 \%$ and $6 \%$ fresh turmeric paste in zobo. This implies that boiled turmeric samples would have higher mineral contents ${ }^{18}$ and this was also proven in this present study as the highest values of iron and zinc were recorded in $2 \%$ and $6 \%$ boiled turmeric in zobo, respectively. Moreover, turmeric has been reported to contain a low ash content, namely of $2.9 \%$. Other medicinal plants contains higher ash contents, such as Acalypha racemosa (13.1\%) and Acalypha marginata (10.3\%). ${ }^{27}$

3.2.3. Crude protein content. A low protein content was found in this study (Table 1). However, addition of turmeric 
seemed to increase protein content. Turmeric contains 6.3\% protein, ${ }^{28}$ which is much higher than the amount of protein found in the zobo control. This was reflected in the zobo with boiled turmeric samples ( $2 \%$ and $6 \%$ ), which contain significantly more protein that the zobo control.

\subsection{Mineral content}

Iron and zinc deficiencies are globally predominant, classified 9th and 11th, respectively, in the category of the main risk factors for world-wide problem of ailment and they mostly occur in developing nations. ${ }^{29}$ The amount of iron and zinc in the water used for zobo preparation was negligible: -0.01 and $0.02 \mathrm{mg} \mathrm{L}^{-1}$ for iron and zinc, respectively. The iron and zinc in the turmeric-fortified zobo were from both the hibiscus calyces and turmeric. The average amounts of iron and zinc in our samples ranged between $10-14 \mathrm{mg} \mathrm{L}^{-1}$ and $2.1-2.7 \mathrm{mg}$ $\mathrm{L}^{-1}$, respectively with the highest values of iron and zinc recorded in $2 \%$ and $6 \%$ boiled turmeric in zobo respectively. These ranges are within the interval reported in literature. ${ }^{30,31}$ In children aged 2 to 5 years, the daily recommended intake of iron is $8 \mathrm{mg}$ and the daily recommended intake of zinc is $6 \mathrm{mg} .{ }^{32,33}$ Consumption of a typical one serving of $500 \mathrm{~mL}$ (representative packaged bottle size of zobo drink by the street vendors) of turmeric-fortified zobo would contribute $63-88 \%$ DV and $18-23 \%$ DV of iron and zinc respectively. In agreement to the recent literature ${ }^{34}$ on the use of nutrition information and understanding of percentage Daily Value (DV) based on the health Canada campaign message (" $5 \%$ DV or less is a little; $15 \%$ DV or more is a lot"), thus, drinking turmeric-fortified zobo would contribute significantly towards the required intake of iron and zinc.

\subsection{Vitamins}

Vitamin $\mathrm{B}_{9}$, or folate, is synthetically produced as folic acid for food fortification and supplementation. Folic acid was detected in all samples containing zobo, whereas no folic acid was found in the turmeric in water samples. Folic acid ranged from 256-301 $\mu \mathrm{g}$ per $100 \mathrm{~mL}$ (Table 2). The Recommended Dietary Allowance (RDA) for adults is $400 \mu \mathrm{g}$ day $^{-1}$, with pregnant and lactating women needing an additional 100-200 $\mu \mathrm{g}$ day $^{-1} \cdot{ }^{35}$ Further $400 \mu \mathrm{g}$ day $^{-1}$ of synthetic folic acid from either supplements or fortified-foods is recommended for females capable of becoming pregnant to lessen the risk of the neural tube defects (NTD). ${ }^{36}$ Drinking turmeric-fortified zobo would contribute in excess to the recommended daily intake of folic acid as one serving contains $320-376 \%$ DV, $213-251 \%$ DV and $160-188 \%$ DV for adults, lactating and women capable of becoming pregnant recommended daily intake respectively. Zobo is usually sold by street vendors in $500 \mathrm{~mL}$ bottles in Nigeria. Hence, drinking a half bottle $(250 \mathrm{~mL})$ is enough to exceed the daily required amount of folic acid for all ages and genders. Adequate daily intake of folic acid is important to prevent neural tube defects, which are four times more likely to occur in developing countries, such as Nigeria, than in developed countries. ${ }^{37}$

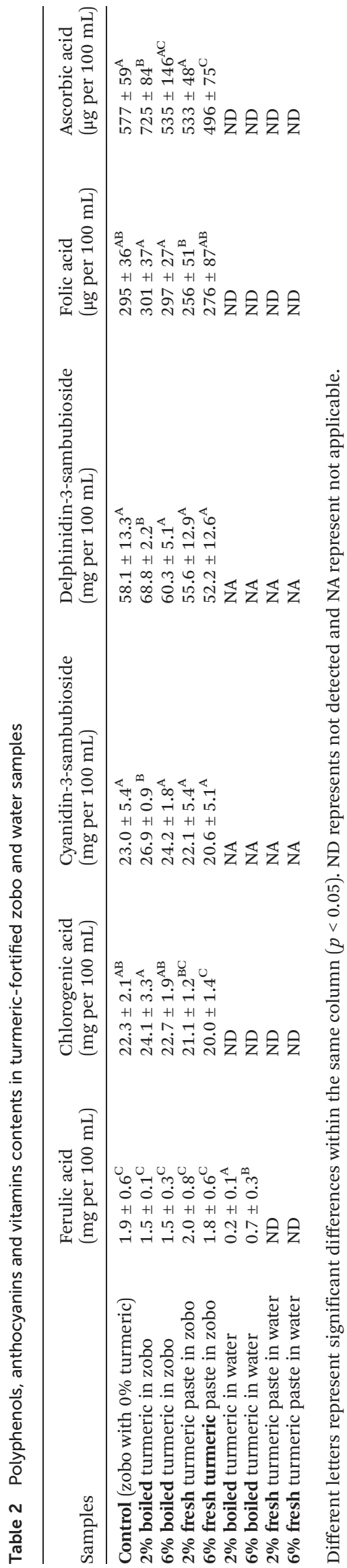


Vitamin $\mathrm{C}$ was measured as the total amount of ascorbic acid. The four control samples containing turmeric in water resulted in no detectable peaks, corroborating that turmeric does not contain ascorbic acid. ${ }^{38}$ The amount of vitamin $\mathrm{C}$ in the samples ranged from 496-725 $\mu \mathrm{g}$ per $100 \mathrm{~mL}$ (Table 2). Samples fortified with $6 \%$ turmeric paste had the lowest value with no significant difference with the zobo boiled with $6 \%$ turmeric root. However, the value found in the control sample $(0 \%$ turmeric) was lower than in other scientific articles, which ranged from $1500-3000 \mu \mathrm{g}$ per $100 \mathrm{~mL} .^{2,39}$ The difference in vitamin $\mathrm{C}$ content could be due to the process applied to dry the $H$. sabdariffa calyces used for production of the zobo, as vitamin $\mathrm{C}$ can be lost through heating. ${ }^{40}$ Additionally, the quantity of $H$. sabdariffa calyces used for the production of zobo also has an effect, as research has shown that vitamin $\mathrm{C}$ content increases when the amount increases from $2 \%$ calyces to $15 \%$ calyces in water. $^{39}$ In this study, the quantity of $H$. sabdariffa calyces used in zobo was $8 \%$. According to the previous research, increasing $H$. sabdariffa calyces above the $8 \%$ used in our study could increase the total ascorbic acid content. The vitamin $\mathrm{C}$ content in the sample with $2 \%$ boiled turmeric in zobo was significantly higher than in all other samples, showing a similar pattern as for the anthocyanin in the samples (Table 2). Ascorbic acid was not detectable in the four control samples containing turmeric in water. The highest value reported in $2 \%$ boiled turmeric in zobo, which was significantly different from the control (zobo with $0 \%$ turmeric), could be attributed to the effect of food-to-food fortification, ${ }^{41}$ as the effect of a bioactive may differ between the whole food (matrix effect) and the isolated compound. ${ }^{42,43}$ Research has also shown that a heat treatment, such as boiling, can release bound antioxidant principles from turmeric, resulting in a higher ascorbic acid content. ${ }^{44}$ Other studies, focusing on curcumin, have suggested that the activity following the heating step could be a result of the degradation products, which provide similar activity. ${ }^{45}$ Vitamin $\mathrm{C}$ contents in $6 \%$ boiled turmeric in zobo appeared to be significantly lower than the vitamin $\mathrm{C}$ content found in $2 \%$ boiled turmeric in zobo, which we suspect to be due to aggregation and/or precipitation at a higher concentration. The Recommended intake for vitamin $\mathrm{C}$ is $75 \mathrm{mg}$ for women and $90 \mathrm{mg}$ for men. ${ }^{46}$ For children, the RDA is $40 \mathrm{mg}$, which is necessary to prevent wasting in sub-Saharan Africa. ${ }^{47}$ The vitamin C content in one serving (one bottle of $500 \mathrm{~mL}$ ) of the $2 \%$ boiled turmeric zobo could moderately ${ }^{34}$ contribute $5 \%$ DV, 4\% DV and 9\% DV for women (75 mg), men (90 mg) and children (40 mg) recommended intake respectively. Addition of fruit juices, common in zobo processing, could increase the overall content of vitamin C. ${ }^{2}$

\subsection{Anthocyanins}

Cyanidin-3-sambubioside has been identified as one of the two major anthocyanin components of $H$. sabdariffa. ${ }^{3,10}$ However, it has not been determined if the addition of turmeric affects the anthocyanin content. Cyanidin-3-sambubioside was present in all zobo samples in a range of $21-27 \mathrm{mg}$ per $100 \mathrm{~mL}$ (Table 2).
It accounts for approximately $30 \%$ of the total anthocyanin content in turmeric-fortified zobo, which is similar to values reported in previous research. An increase in the amount of calyces used for production and boiling time of the turmericfortified zobo beverage could potentially result in a higher quantities of total anthocyanins found in this study.

Turmeric-fortified zobo processed with $2 \%$ boiled turmeric is significantly higher in Cyanidin-3-sambubioside than all other samples. This is in line with the theory explained in the vitamin $\mathrm{C}$ section, stating that heat treatment of turmeric can impact other compounds. As turmeric alone contains no anthocyanins, heat treatment cannot release bound anthocyanin principles. Rather, the heat treatment can result in degradation products that act similarly to anthocyanins. ${ }^{45}$

Delphinidin-3-sambubioside is the other primary anthocyanin in H. sabdariffa. ${ }^{3,10}$ Delphinidin-3-sambubioside in the turmeric-fortified zobo is present in a range of 52-69 $\mathrm{mg}$ per $100 \mathrm{~mL}$ (Table 2). Delphinidin-3-sambubioside constitutes approximately $70 \%$ of the total anthocyanins, across all samples. This result correlates with previous research, which has shown that delphinidin-3-sambubioside accounts for between $75-85 \%$ of the total anthocyanins in zobo. ${ }^{48,49}$

The effect of turmeric processing has similar outcomes for both delphinidin-3-sambubioside and cyanidin-3-sambubioside. The highest amount of delphinidin-3-sambubioside was recorded for $2 \%$ boiled turmeric in zobo, as $69 \mathrm{mg}$ per $100 \mathrm{~mL}$ was significantly higher than the contents of all other samples. In fresh calyces of $H$. sabdariffa, both delphinidin-3sambubioside and cyanidin-3-sambubioside have concentrations more than double of that found in the turmeric-fortified zobo beverage. ${ }^{48}$ The significant loss of anthocyanins is most likely due to heat degradation during drying. ${ }^{50}$ Juhari et $a .^{3}{ }^{3}$ confirmed that variation in the anthocyanin content of $H$. sabdariffa calyces grown in different countries was mainly due to sun drying.

Addition of food-grade organic acids has been reported to improve anthocyanin stability. ${ }^{10}$ These findings were corroborated by the increase in the anthocyanin content of the $2 \%$ boiled turmeric zobo. This increased amount of anthocyanins could contribute to the anti-inflammatory, visual and neurological-health improving properties of turmeric-fortified zobo. ${ }^{51,52}$

\subsection{Ferulic and chlorogenic acid}

H. sabdariffa contains several polyphenols: chlorogenic acid, hydroxycitric acid, protocatechuic acid, quercetin, ferulic acid, and caffeic acid. ${ }^{22,53,54}$ In an exploratory trial at the beginning of this study, the peaks with the largest area were determined to identify the polyphenols present in the highest concentrations. The polyphenols analyzed via HPLC for identification were: caffeic acid, ferulic acid, protocatechuic acid, gallic acid, quercetin, catechin, rutin, naringin, benzoic acid, and chlorogenic acid. Five major peaks (Fig. 3) were consistently found in either zobo or boiled turmeric in water, namely ferulic acid, chlorogenic acid, two anthocyanin peaks, and a major polyphenol peak that remained unknown. The anthocyanin peaks 


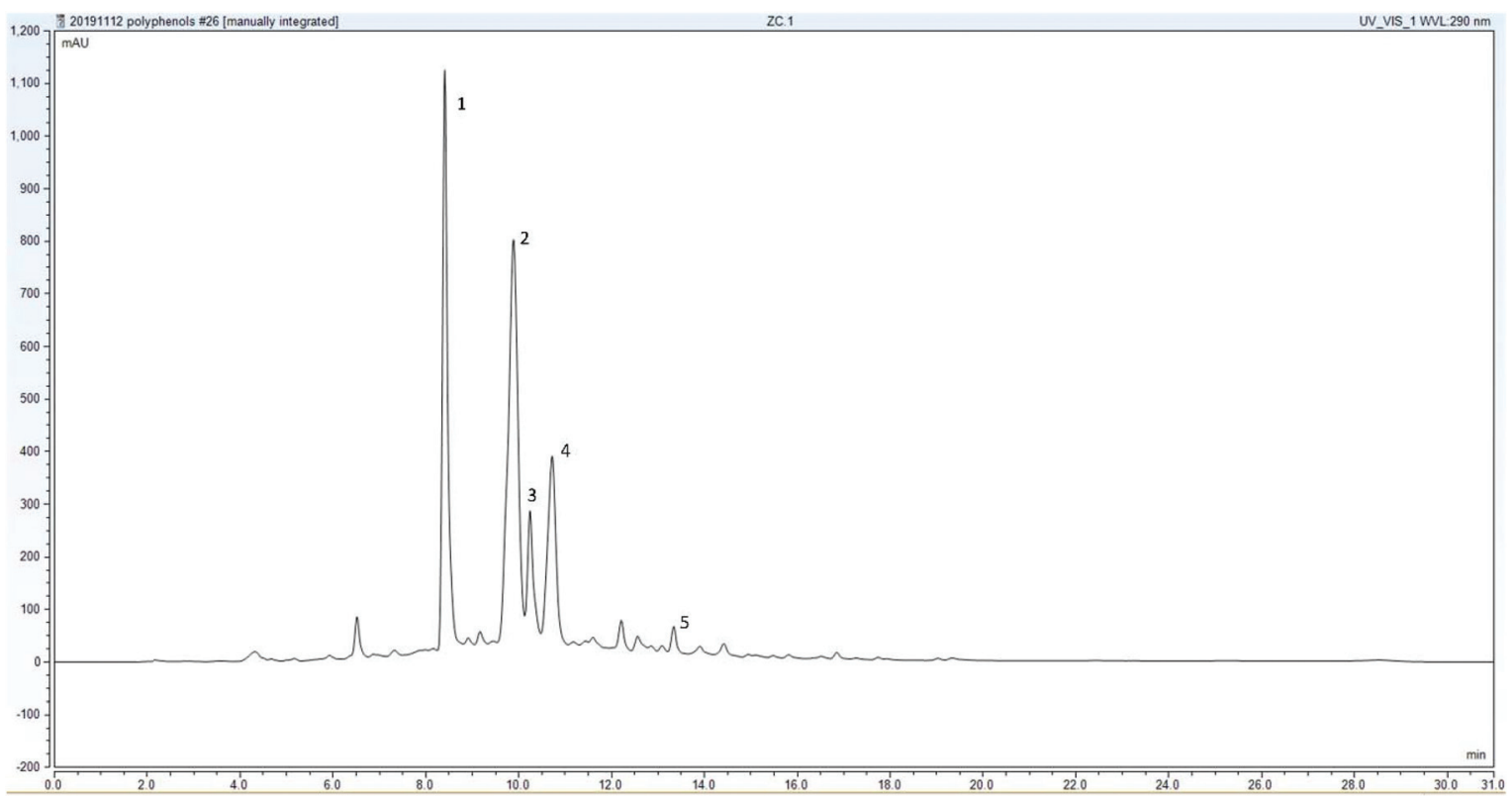

Fig. 3 HPLC chromatogram of zobo control polyphenol extraction. Peak profiles of (1) unknown peak, (2) cyanidin-3-sambubioside, (3) chlorogenic acid, (4) delphinidin-3-sambubioside, and (5) ferulic acid.

were characterized by their high UV maximum (515 nm). These peaks were identified as cyanidin-3-sambubioside and delphinidin-3-sambubioside. The two other main peaks were phenolic acids, namely ferulic acid and chlorogenic acid.

3.6.1. Ferulic acid. Ferulic acid was detected in seven samples, in a range of $0.16-2.03 \mathrm{mg}$ per $100 \mathrm{~mL}$ (Table 2), including those samples in which turmeric was added to water. These results agree with previous research that states that ferulic acid is present in turmeric, as a major decomposition product of curcumin. ${ }^{15,38}$ The absence of ferulic acid in the fresh turmeric paste in water samples is attributed to the absence of a heat treatment. Ferulic acid is typically formed after thermal degradation of curcumin. ${ }^{15}$

The zobo and the turmeric-fortified zobo did not differ in the quantities of ferulic acid they contained. This demonstrates that turmeric, whether boiled or in paste form, does not affect the total ferulic acid in turmeric-fortified zobo in the quantities that we tested. The only two samples with significantly lower amounts were the water samples with boiled turmeric. Yet, when $6 \%$ of turmeric was added instead of $2 \%$, the total ferulic acid content significantly increased. This shows that more heat degradation products are formed with a higher amount of added turmeric. According to Vankar et al., ${ }^{44}$ the boiling of turmeric could potentially release bound antioxidant principles, which could allow for a detectable amount of ferulic acid. Other research has also shown that total phenolic content can increase after heat treatment due to the inactivation of polyphenol oxidase. ${ }^{55}$ This supports the findings that turmeric paste in water has no detectable ferulic acid or phenolics. In the zobo samples, most of the ferulic acid originated from $H$. sabdariffa, making the differences between boiled turmeric and turmeric paste insignificant. The processing of tur- meric had no impact on the overall ferulic acid content, making the addition of turmeric not an extra source of ferulic acid in zobo.

3.6.2. Chlorogenic acid. Chlorogenic acid only was present in samples containing $H$. sabdariffa, in line with previous research. ${ }^{22,31}$ The range of chlorogenic acid is approximately 20-24 mg per $100 \mathrm{~mL}$ (Table 2). There is no significant difference between the zobo control and zobo samples fortified with boiled turmeric, which shows that the addition of boiled turmeric does not increase the chlorogenic acid content of zobo. Addition of turmeric paste to zobo slightly lowered the chlorogenic acid content. We contribute this effect to natural variation in the raw material in the absence of scientific knowledge that would indicate otherwise. Previous research has found isomers of chlorogenic acid in dried $H$. sabdariffa leaves, specifically neochlorogenic acid and cryptochlorogenic acid. ${ }^{56}$ We expect that the unknown peak in Fig. 3 is a stereoisomer of chlorogenic acid.

\section{Conclusions}

The present study contributes to the potential utilization of turmeric root in the production of street-vended zobo drink. The results show that the antioxidant and nutritional quality of zobo (H. sabdariffa) drink can be improved by the way of processing (heating/boiling) and the addition of a second ingredient (i.e. turmeric) which could be easily adopted by the street vendors in Nigeria. Nowadays there is an increasing awareness of the relation between food intake and health, which has boosted the demand for health-supporting food products by consumers. Ascorbic acid, cyanidin-3-sambubio- 
side, delphinidin-3-sambubioside, ferulic acid, and chlorogenic acid were present in turmeric-fortified zobo. Overall, the addition of $2 \%$ boiled turmeric in street-vended zobo could contribute beneficially to the Nigerian diet, due to the increased content of vitamin $\mathrm{C}$ and anthocyanins. Thus, by inclusion of turmeric in zobo production street-vendors can prepare what consumers want to be able to make healthier food choices. Presently the Nigerian Government is promoting the turmeric crop, which is relatively cheap and widely available within the country, hence making turmeric-fortified zobo affordable for the public.

The heat treatment applied in our study resulted in increased concentrations of vitamin $\mathrm{C}$ and anthocyanins. Further research is needed to determine the binding, precipitation, or aggregation effects that play a role at higher concentrations of boiled turmeric $(6 \%)$ in zobo. We followed the traditional processing methods of the zobo street vendors in this study by boiling the zobo with the turmeric. Addition of turmeric powder to zobo instead of turmeric paste could be another processing method that warrants follow-up research. Studies of the effect of turmeric-fortification on other streetvended drinks like soymilk, which is rich in protein, are also recommended to determine the influence of a different food matrix.

\section{Conflicts of interest}

There are no conflicts to declare.

\section{Acknowledgements}

This study was financially supported by the Tertiary Education Trust Fund (TETFund) of Nigeria, 2015 Academic Staff Training and Development intervention for Federal University Oye-Ekiti (FUOYE), Nigeria.

\section{References}

1 N. P. Steyn, Z. Mchiza, J. Hill, Y. D. Davids, I. Venter, E. Hinrichsen, M. Opperman, J. Rumbelow and P. Jacobs, Nutritional contribution of street foods to the diet of people in developing countries: a systematic review, Public Health Nutr., 2014, 17, 1363-1374.

2 S. C. Izah, L. A. Orutugu and L. T. Kigigha, A review of the quality assessment of zobo drink consumed in Nigeria, ASIO J. Microbiol. Food Sci. Biotechnol. Innovations, 2015, 1, 34-44.

3 N. H. Juhari, W. L. P. Bredie, T. B. Toldam-Andersen and M. A. Petersen, Characterization of Roselle calyx from different geographical origins, Food Res. Int., 2018, 112, 378-389.

4 G. Riaz and R. Chopra, A review on phytochemistry and therapeutic uses of Hibiscus sabdariffa L, Biomed. Pharmacother., 2018, 102, 575-586.
5 A. Bechoff, M. Cissé, G. Fliedel, A.-L. Declemy, N. Ayessou, N. Akissoe, C. Touré, B. Bennett, M. Pintado and D. Pallet, Relationships between anthocyanins and other compounds and sensory acceptability of Hibiscus drinks, Food Chem., 2014, 148, 112-119.

6 N. Mohd-Esa, F. S. Hern, A. Ismail and C. L. Yee, Antioxidant activity in different parts of roselle (Hibiscus sabdariffa L.) extracts and potential exploitation of the seeds, Food Chem., 2010, 122, 1055-1060.

7 I. Jabeur, E. Pereira, L. Barros, R. C. Calhelha, M. Soković, M. B. P. Oliveira and I. C. Ferreira, Hibiscus sabdariffa L. as a source of nutrients, bioactive compounds and colouring agents, Food Res. Int., 2017, 100, 717-723.

8 Y. Xu, D. Hu, T. Bao, J. Xie and W. Chen, A simple and rapid method for the preparation of pure delphinidin-3-Osambubioside from Roselle and its antioxidant and hypoglycemic activity, J. Funct. Foods, 2017, 39, 9-17.

9 G. Mercado-Mercado, F. J. Blancas-Benitez, G. R. Velderrain-Rodríguez, E. Montalvo-González, G. A. González-Aguilar, E. Alvarez-Parrilla and S. G. SáyagoAyerdi, Bioaccessibility of polyphenols released and associated to dietary fibre in calyces and decoction residues of Roselle (Hibiscus sabdariffa L.), J. Funct. Foods, 2015, 18, 171-181.

10 I. F. Pérez-Ramírez, E. Castaño-Tostado, J. A. Ramírez-de León, N. E. Rocha-Guzmán and R. Reynoso-Camacho, Effect of stevia and citric acid on the stability of phenolic compounds and in vitro antioxidant and antidiabetic capacity of a roselle (Hibiscus sabdariffa L.) beverage, Food Chem., 2015, 172, 885-892.

11 A. O. Omotayo, Correlates of hunger severity and food intake among rural household in Nigeria: Facing the key challenges of the $21^{\text {st }}$ century, Socioeconomica, 2018, 7, 5376.

12 O. Dary and R. Hurrell, Guidelines on food fortification with micronutrients, World Health Organization, Food and Agricultural Organization of the United Nations, Geneva, 2006.

13 J. Nwaekpe, H. Anyaegbunam, B. Okoye and G. Asumugha, Promotion of turmeric for the food/pharmaceutical industry in Nigeria, J. Exp. Agric. Int., 2015, 335-341.

14 A. Trifan, A. C. Aprotosoaie and A. Miron, Curcumin in Food, Handbook of Dietary Phytochemicals, 2019, pp. 1-44.

15 N. A. Siddiqui, Evaluation of thermo sensitivity of curcumin and quantification of ferulic acid and vanillin as degradation products by a validated HPTLC method, Pak. J. Pharm. Sci., 2015, 28, 299-305.

16 E. de Oliveira Silva and R. Batista, Ferulic acid and naturally occurring compounds bearing a feruloyl moiety: a review on their structures, occurrence, and potential health benefits, Compr. Rev. Food Sci. Food Saf., 2017, 16, 580-616.

17 J. O. Ekanem, Microbial, sensory and nutritional properties of laboratory prepared sorrel (zobo) drinks fortified with spices and sugar, J. Global Biosci., 2018, 7, 5573-5584.

18 S. G. Sáyago-Ayerdi, S. Arranz, J. Serrano and I. Goñi, Dietary fiber content and associated antioxidant com- 
pounds in roselle flower (Hibiscus sabdariffa L.) beverage, J. Agric. Food Chem., 2007, 55, 7886-7890.

19 E. Temminghoff and V. Houba, Plant analyses procedures, Kluwer Academic Publishers, Dodrecht, The Netherlands, 2004.

20 C.-H. Chen, Y.-H. Yang, C.-T. Shen, S.-M. Lai, C.-M. J. Chang and C.-J. Shieh, Recovery of vitamins B from supercritical carbon dioxide-defatted rice bran powder using ultrasound water extraction, J. Taiwan Inst. Chem. Eng., 2011, 42, 124-128.

21 Y. Hernández, M. G. Lobo and M. González, Determination of vitamin $\mathrm{C}$ in tropical fruits: A comparative evaluation of methods, Food Chem., 2006, 96, 654-664.

22 R. Beltrán-Debón, C. Alonso-Villaverde, G. Aragonès, I. Rodríguez-Medina, A. Rull, V. Micol, A. Segura-Carretero, A. Fernández-Gutiérrez, J. Camps and J. Joven, The aqueous extract of Hibiscus sabdariffa calices modulates the production of monocyte chemoattractant protein-1 in humans, Phytomedicine, 2010, 17, 186-191.

23 I. Adesokan, O. Abiola, M. Adigun and O. Anifowose, Analysis of quality attributes of Hibiscus sabdariffa (zobo) drinks blended with aqueous extract of ginger and garlic, Afr. J. Food Sci., 2013, 7, 174-177.

24 P. Adeniji, Nutritional, Sensory and Microbiological Quality Assessment of fortified Zobo Drink: A Home-Prepared Traditional Nigerian Beverage, J. Nutr. Food Sci., 2017, 7, 2.

25 A. Adelekan, N. Arisa, A. Alamu, Y. Adebayo and G. Popoola, Production and acceptibility of fruits enhanced zobo drink, Food Sci. Technol. Lett., 2014, 5, 046-051.

26 O. Ezearigo, P. Adeniji and F. Ayoade, Screening of natural spices for improving the microbiological, nutritional and organoleptic qualities of the Zobo drink, J. Appl. Biosci., 2014, 76, 6397-6410.

27 A. Ikpeama, G. Onwuka and C. Nwankwo, Nutritional composition of Tumeric (Curcuma longa) and its antimicrobial properties, Int. J. Sci. Eng. Res., 2014, 5, 10851089.

28 I. Chattopadhyay, K. Biswas, U. Bandyopadhyay and R. K. Banerjee, Turmeric and curcumin: Biological actions and medicinal applications, Curr. Sci., 2004, 87, 44-53.

29 H. Shumoy, S. Lauwens, M. Gabaza, J. Vandevelde, F. Vanhaecke and K. Raes, Traditional fermentation of tef injera: Impact on in vitro iron and zinc dialysability, Food Res. Int., 2017, 102, 93-100.

30 S. Cid-Ortega and J. Guerrero-Beltrán, Roselle calyces (Hibiscus sabdariffa), an alternative to the food and beverages industries: a review, J. Food Sci. Technol., 2015, 52, 6859-6869.

31 N. M. Karaaslan, A comprehensive study about Hibiscus sabdariffa leaves: antioxidant activity, polyphenol profile and macro-and micro-element content, Chem. Pap., 2019, 73, 791-799.

32 Voedingscentrum, Journal, Ijzer, https://www.voedingscentrum.nl/encyclopedie/foliumzuur.aspx, 2018.

33 Voedingscentrum, Journal, Zink, https://www.voedingscentrum.nl/encyclopedie/ijzer.aspx, 2018.
34 B. Cormier, L. Vanderlee and D. Hammond, Use of Nutrition Information and Understanding of" Percent Daily Value" on Nutrition Facts Tables: Evaluating the Impact of a National Public Education Campaign among Youth and Young Adults in Canada, Can. J. Diet. Pract. Res., 2019, 80, 200-204.

35 L. B. Bailey and J. F. Gregory III, Folate metabolism and requirements, J. Nutr., 1999, 129, 779-782.

36 J. L. Simpson, L. B. Bailey, K. Pietrzik, B. Shane and W. Holzgreve, Micronutrients and women of reproductive potential: required dietary intake and consequences of dietary deficiency or excess. Part I-folate, vitamin B12, vitamin B6, J. Matern.-Fetal Neonat. Med., 2010, 23, 13231343.

37 T. A. Lawal and A. O. Adeleye, Determinants of folic acid intake during preconception and in early pregnancy by mothers in Ibadan, Nigeria, Pan Afr. Med. J., 2014, 19, 113.

38 G. S. Kumar, H. Nayaka, S. M. Dharmesh and P. Salimath, Free and bound phenolic antioxidants in amla (Emblica officinalis) and turmeric (Curcuma longa), J. Food Compos. Anal., 2006, 19, 446-452.

39 A. Obadina and O. Oyewole, Assessment of the antimicrobial potential of roselle juice (zobo) from different varieties of roselle calyx, J. Food Process. Preserv., 2007, 31, 607-617.

40 S. Fasoyiro, S. Babalola and T. Owosibo, Chemical composition and sensory quality of fruit-flavoured roselle (Hibiscus sabdariffa) drinks, World J. Agric. Sci., 2005, 1, 161-164.

41 U. Onoja, P. Akubor, D. Gernar and C. Chinmma, Evaluation of complementary food formulated from local staples and fortified with calcium, iron and zinc, J. Nutr. Food Sci., 2014, 4, 1-6.

42 P. J. Moughan, Holistic properties of foods: a changing paradigm in human nutrition, J. Sci. Food Agric., 2020, 100, 5056-5063.

43 N. A. Nasef, S. M. Loveday, M. Golding, R. N. Martins, T. M. Shah, M. Clarke, J. Coad, P. J. Moughan, M. L. Garg and H. Singh, Food matrix and co-presence of turmeric compounds influence bioavailability of curcumin in healthy humans, Food Funct., 2019, 10, 4584-4592.

44 V. Tiwari, R. Shanker, J. Srivastava and P. S. Vankar, Change in antioxidant activity of spices-turmeric and ginger on heat treatment, Electron. J. Environ., 2006, 5, 1313-1317.

45 L. Shen, H.-H. Jiang and H.-F. Ji, Is boiled food spice curcumin still biologically active? An experimental exploration, Food Nutr. Res., 2018, 62, 1-8.

46 R. A. Jacob and G. Sotoudeh, Vitamin C function and status in chronic disease, Nutr. Clin. Care, 2002, 5, 66-74.

47 D. K. Matilsky, K. Maleta, T. Castleman and M. J. Manary, Supplementary feeding with fortified spreads results in higher recovery rates than with a corn/soy blend in moderately wasted children, J. Nutr., 2009, 139, 773-778.

48 A. Piovesana, E. Rodrigues and C. P. Z. Noreña, Composition analysis of carotenoids and phenolic com- 
pounds and antioxidant activity from hibiscus calyces (Hibiscus sabdariffa L.) by HPLC-DAD-MS/MS, Phytochem. Anal., 2019, 30, 208-217.

49 P. J. Tsai, J. Mclntosh, P. Pearce, B. Camden and B. R. Jordan, Anthocyanin and Antioxidant capacity in roselle (Hibiscus sabdariffa L.) extract, Food Res. Int., 2002, 35, 351-356.

50 L. Havlíková and K. Míková, Heat stability of anthocyanins, Z. Lebensm.-Unters. Forsch., 1985, 181, 427-432.

51 H. E. Khoo, A. Azlan, S. T. Tang and S. M. Lim, Anthocyanidins and anthocyanins: colored pigments as food, pharmaceutical ingredients, and the potential health benefits, Food Nutr. Res., 2017, 61, 1361779.

52 T. Sogo, N. Terahara, A. Hisanaga, T. Kumamoto, T. Yamashiro, S. Wu, K. Sakao and D. X. Hou, Anti-inflammatory activity and molecular mechanism of delphinidin 3-sambubioside, a Hibiscus anthocyanin, BioFactors, 2015, 41, 58-65.
53 I. Da-Costa-Rocha, B. Bonnlaender, H. Sievers, I. Pischel and M. Heinrich, Hibiscus sabdariffa L.-A phytochemical and pharmacological review, Food Chem., 2014, 165, 424443.

54 S. Kakkar and S. Bais, A review on protocatechuic acid and its pharmacological potential, ISRN Pharmacol., 2014, 2014, 952943.

55 A. Prathapan, M. Lukhman, C. Arumughan, A. Sundaresan and K. Raghu, Effect of heat treatment on curcuminoid, colour value and total polyphenols of fresh turmeric rhizome, Int. J. Food Sci. Technol., 2009, 44, 1438-1444.

56 J. Wang, X. Cao, H. Jiang, Y. Qi, K. L. Chin and Y. Yue, Antioxidant activity of leaf extracts from different Hibiscus sabdariffa accessions and simultaneous determination five major antioxidant compounds by LC-Q-TOF-MS, Molecules, 2014, 19, 21226-21238. 